\title{
The Use of Digital Technologies in Logistics Systems
}

\author{
Dyomin V.A. ${ }^{1}$ Efimenko D.B. ${ }^{1}$ Moiseev V.V. ${ }^{2, *}$ Komkova D.A. ${ }^{1}$
}

\author{
${ }^{1}$ Moscow Automobile and Road State Technical University (MADI), Moscow, Russia \\ ${ }^{2}$ Belgorod State Technological University named after V.G. Shukhov, Belgorod, 308012, Russia \\ *Corresponding author. Email: din_prof@mail.ru
}

\begin{abstract}
This article discusses issues related to freight transport by road and their place in the logistics system. Based on the analysis of the current situation in the Russian economy and the modern logistics system, the need for improving the process using ITS technologies is revealed. Due to the lack of effective development of such sectors of the Russian economy as industry and trade, the article presents possible options for the use of automatic identification technologies in transport and logistics systems to increase the efficiency of truck transport and the main indicators of the effectiveness of this technology. The article discusses the process of applying automatic identification and indicates the features of their application on each section of the supply chain. The rules of work for participants in the supply chain (production, transportation by road, warehouse or trade enterprise) using radio frequency identification have been developed due to the current need for standard technological solutions and the lack of common standards. The classification and recommendations of the probing signal when using radio frequency identification are indicated. Also given recommendations on the use and tuning of RFID transponders depending on the properties of the cargo, the size of the cargo unit and how they are stacked. The article briefly presents the possible benefits of improving the functioning of road freight transport in logistics systems using automatic identification.
\end{abstract}

Keywords: model, technology, freight vehicles, radio frequency identification, logistics system, intelligent

transport systems

\section{INTRODUCTION}

In modern conditions, the sustainable development of the economy of Russia, its regions, and large cities requires optimization of logistics costs over the full product life cycle in the processes of production, storage, transportation, marketing, operation, after-sales service and disposal. The solution to this problem is impossible without modernization of the material and technical and technological base of enterprises, the use of modern equipment and information technologies in the implementation of most logistics operations. The modern development of logistics is inextricably linked with the introduction of digital technology [1]. Creating a logistics infrastructure at a qualitatively new level is associated with the need to improve integration processes using ITS technologies, including automatic identification systems.

RFID today is considered as a unique technology of contactless identification of objects, which gives significant advantages over all known methods of marking and identification. RFID solutions are in demand both in large logistics centers and in enterprises of various industries: electronic, food, pharmaceutical, aircraft and engineering, etc.

Despite the active development of technology, a significant part of the tasks associated with the use of RFID in various industries and technological conditions remains unresolved [2, c.8]. Currently, there is a need to develop methods, models and regulations for managing the interaction of elements of the transport and logistics system using radio frequency identification systems, since today there are no standard technological solutions and common standards on a global scale. This circumstance is due to the use in different countries of different frequency ranges for radio frequency identification systems, the lack of a unified technology for managing interactions in the transport and logistics system and approaches to RFID integration.

\section{BACKGROUND}

At present, according to the research carried out by the World Bank, Russia takes the 75 place (of 160 countries) in the level of logistical system performance [3]. In Russia, in the final product's cost composition, logistics costs make up 35-40\%, which is 1.7-1.8 times higher, than in the countries of European Community. These costs can be reduced by at least $3-5 \%$ (which would make up about 3.7 trln rubles) in case of improving the consumer service by applying automatic identification technologies in transport-and-logistics systems, the issues of using which is an object of this applied scientific research. The role of transport-and-logistics system of the Russian Federation is determined not only by its economic indices, but also by its ability to influence other activities. At the same time, by now in the transport-and-logistics system of the Russian Federation a sizable list of problems has formed, 
without solving which the efficient functioning of economic entities is not possible. The transport infrastructure's nonconformance to transportation demands, and lack of planning and traffic flows control system results in the waits at main traffic arteries, and the speed is reduced by $50-70 \%$ in comparison with the indices of the European Community countries. So, it is no coincidence that at present special attention is paid to improving the level of logistic service in such parameters as accuracy, timeliness and reliability [4, p. 14]. Analyzing the transport problems of the country, we can make a conclusion that such problems are first of all caused by low traffic capacity of transport-and-logistics systems of the regions and the country in general, which results from the high load on transport infrastructure due to the chaotic arrangement of storing and cargo-generating facilities across the country.

A special role in transport-and-logistic system of the country is played by the functioning of road freight transport, the share of which in the whole volume of cargo transportation amounts, according to the data of the Analytical Centre of the Government of the Russian Federation, to $67.1 \%$ (in 2018) [5, p.3]. Besides, the technological characteristics of the motor transport functioning, expressed in the possibility of the «flexible», «doorto-door» delivery, form the strategic importance of this means of transport in logistical systems.

At the same time, certain problems have formed in road freight transport functioning, without solving which the further efficient development of such sectors of the Russian economy as industry and trade, are not possible. So, the low useful time coefficient of using motor vehicles shows that (deducting the time, required for maintenance and repair) cargo-handling operations and queuing time take almost half of the total time of transport activity. Such situation, according to Adil Gadzhinsky, professor of RSUTE and logistics expert, results from the low level of warehousing infrastructure [6].

Another problem is the products quality control and providing special temperature-sensitive conditions at transportation and storage. At present the application of technological solutions, which would allow solving this task, is at a very low level.

The specific transport work index at product delivery in Russia surpasses those of the most developed regions in the European Community countries by 1.7 times, due to the inefficient cargo traffic distribution system at product delivery [7]. Such situation is caused by the following factors:

lack of high-quality infrastructure in corresponding transporting areas (terminals and warehouses),

lack of information about cargo traffic and, as a result, inefficient cargo traffic distribution at product delivery from South-East Asia to the regions of the Russian Federation.

Thus, the cargo, delivered by railway from China to Moscow, arrives after 1-2 months to the Transbaikal region, including the usage of road freight transport. So, at the same volume of the delivered product the transportation work increases by 1.5-1.7 times due to the increase of the delivery distance.

All the above-mentioned problems result in the fact, that with fuels and lubricants costs and salary budget 2-3 times lower than in Central and Western Europe countries, the motor-transport logistics freight rates in Russia are higher than the similar rates in the European Community, which in its turn preconditions the inflated prices for any products, manufactured or sold at the territory of our country. Those and other shortcomings of the national transport system were noted in the official document «Transport strategy of the Russian Federation for the period up to 2030» [8].

\section{PURPOSE OF STUDY}

The main objective of the authors of this study was to develop a work schedule for supply chain participants using radio frequency identification and other digital technologies to increase the efficiency of interaction of freight motor transport systems in all areas of the transport and logistics system of the Russian Federation.

\section{RESEARCH QUESTIONS}

In this study, the author considers the following questions.

1. One of the main issues, considered by the authors, is the topical problems of application of ITS technologies in logistical systems with the usage of digital technologies.

2. The necessity of developing methods, models and control instructions for the interaction of transportlogistic system's elements with the usage of radio frequency identification system is substantiated.

3 . On the basis of the carried-out research proposals are made for creating schemes of optimizing the technological process of product movement.

\section{RESEARCH METHODS}

In this study, the following methods are used: comparative, institutional, systemic and structuralfunctional.

Nowadays most of innovative technological solutions in road freight transport are developed and implemented (at the level of technology, equipment and control systems) in such countries as: Germany, Sweden, the USA, Japan etc. [9]. The existing methods and models of road freight transport functioning in logistical systems, developed abroad, don't take into account the peculiarities of the existing material flows distribution structure, peculiarities of the transport system, infrastructure and geographical conditions of the Russian Federation.

Development and production of technological solutions by Russian enterprises has only a slight share at the Russian and world market. This is caused by the low financing of the «research and development» area, and the long cycle of launching a designed solution to the market. At the same time, the prime cost of the Russian equivalents of technological equipment, for example, in such sphere as automatic identification is 7-8 times lower, than of the similar equipment in the mentioned countries [10]. But at this positive factor it should be pointed out that the technological variety of finished products is by an order inferior to their production in the abovementioned countries, and this, in its turn, preconditions the low demand level for domestic products, as not providing the solution for all problems in this sphere. 
In conditions of high dependence on foreign-made technologies, necessary for the efficient functioning of the motor-transport sector in Russia, the topicality of the domestic research and production is vitally important, also in the context of performing import substitution at the required level of quality [11].

At present various technologies, belonging to the class of automatic identification, have been developed, which can be used for improving the efficiency of road freight transport functioning in logistical systems. But the efficiency of using these solutions is rather low due to a number of local shortcomings in technologies themselves and lack of methods and models, which can allow integrating technical means and processes.
The implementation of radio-frequency identification technology allows developing a scheme of optimizing the technological process of product movement from manufacturing enterprises through shopping, distributing and logistics centers to the consumer. For the efficient work of RFID technology the probing signal power for the best information reading from a transponder should be determined.

GOST R ISO 17363-2010 [12] standardizes the radio frequencies range, which are used for each link of the chain. There are 5 levels for each type, presented in Table 1.

\section{DATA RECEIVED}

Table 1 Radio-frequency range

\begin{tabular}{|l|l|l|}
\hline Level & Radio frequencies & Type of unit \\
\hline Level 0 & $\begin{array}{l}13.56 \mathrm{MHz}-18000-3 \mathrm{~m} 3 \\
860-960 \mathrm{MHz}-18000-6 \mathrm{~s}\end{array}$ & Load unit \\
\hline Level 1 & $\begin{array}{l}13.56 \mathrm{MHz}-18000-3 \mathrm{~m} 3 \\
860-960 \mathrm{MHz}-18000-6 \mathrm{~s}\end{array}$ & Packaging of product \\
\hline Level 2 & $13.56 \mathrm{MHz}-18000-3 \mathrm{~m} 3$ & \\
& $860-960 \mathrm{MHz}-18000-6 \mathrm{~s}$ & Transported unit \\
\hline Level 3 & $(860-960 \mathrm{MHz}-18000-6 \mathrm{~s})$ & Returnable transport items (RTIs) \\
& $433 \mathrm{MHz}-18000-7$ & \\
& $13.56 \mathrm{MHz}-18000-3 \mathrm{~m} 3$ & \\
& $<135 \mathrm{kHz}-18000-2 \mathrm{~A}$ & \\
\hline Level 4 & $433 \mathrm{MHz}-18000-7$ & Cargo containers \\
& & Means of transport \\
\hline
\end{tabular}

A. Technological process at products manufacturing Transport-logistic system is a set of interconnected elements, which include cargo-generating objects (primary production, materials production, finished-product output), objects of transport (rolling stock, warehouses, terminals, logistics centers) and road infrastructure, cargo receivers (consumers) of various types (final consumers, i.e. enterprises and physical entities which use the product, and intermediate ones, which are necessary for bringing the product to consumer, such as trading enterprises), recycling facilities [13].

Besides, the transport-logistics system includes transit cargo traffic. Supply chain is an integral part of logistics system.

Supply chain implies the organization, planning, control and regulation of commodity flow. Supply chain has several links from manufacturing of products to the delivery of products to final consumer.

Manufacturing of products is the first link of the chain. At the stage of product manufacturing it is necessary to determine the inventory, subject to RFID-coding and the format of cargo units. To determine the format of cargo units, as a primary cargo unit the cargo in transportation packing, for example, in crates, barrels, sacks etc, is taken. As an aggregative cargo unit a cargo pack, formed of a pallet of primary cargo units, i.e. cargo units in transportation packing, depending on the scope of delivery, can be considered.
This procedure includes determining the maximum possible amount of cargo units for placing them on a pallet, variants of stowage and the probing signal power.

For the efficient carrying-out of the previous stage the standards of cargo units' stowage should be developed. The RFID system testing allows determining the maximum possible amount of cargo units on a pallet, variants of cargo units' stowage, antennae arrangement geometry, and the probing signal power for the best quality of information reading from RFID-transponders.

The RFID system testing at this stage allows determining the main parameters of the system, which appear in the course of product units marking and their stowage on a pallet, in a package or on a loader. The RFID system testing identifies the number of readings for each marked item. For each type of the cargo one of the main variants of its allocation on pallets can be used as shown in Fig. 1: «cube» allocation (a), «relative cylinder» allocation (б), «well» allocation (в), «relative empty cylinder» allocation $(\Gamma)$. 

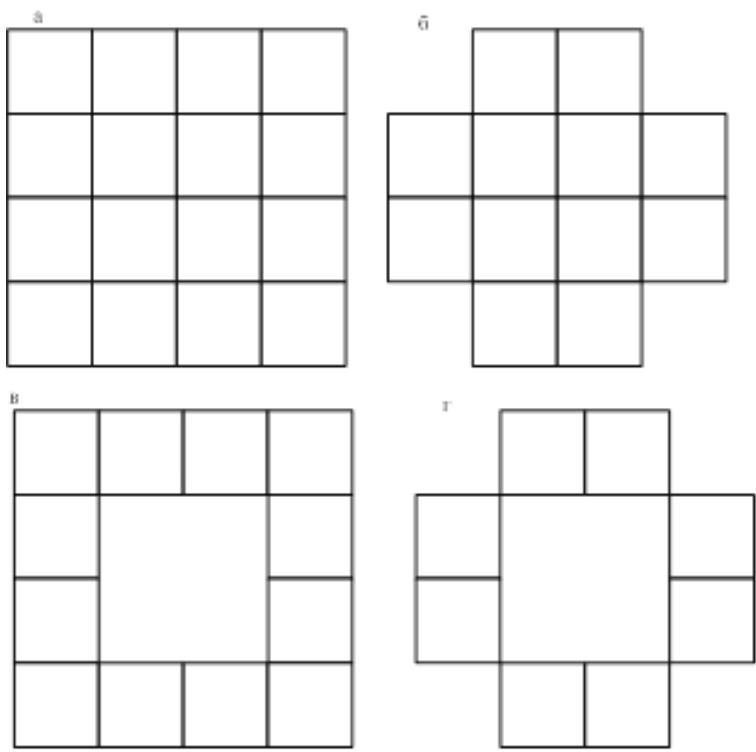

Figure 1 Variants of cargo allocation on pallets

The following points deal with determining the types of used transponders, forming information for recording it on a RFIDtransponder and synchronization it with the automated control system, attaching of the RFID-transponder to a cargo unit, recording information for the transponder.

When attaching a transponder to a cargo unit, one should select the place of a transponder's location on the cargo unit, the best position of the RFID-transponder on each item, in order to improve the information reading and to prevent information loss. Selection of the RFID-transponder location can be influenced by the following factors:

chemical and physical composition of the packing (metal or plastic, smooth or rough surface) and relative distance between a transponder and the surface;

the size of transponder in comparison with the size of the surface; the shape of transponder in comparison with the shape of the surface (transponder must be firmly attached) ;

relative distance between the surface of an item and the packing/item at the lower level;

necessity to protect the transponder from failure, erasure, adverse environmental conditions;

method of cargo units allocation on pallets.

The next stage is data reading from the transponder upon release, which is necessary for storing information about the dispatched cargo by the manufacturer. Due to this procedure the forwarding documents for the cargo are formed.

At the stage of recording data on a RFID transponder of the vehicle, the information about properties (parameters) of the transport means are included. The data are recorded through the radio-frequency channel interface. Then the transponder is attached to the vehicle.

At the concluding stage of the technological process including radio frequency identification in logistics system at products' manufacturing, the check reading procedure is performed and the information is sent to the customer about the dispatched cargo, means of transport and the dispatch time.
B. Process of transport identification and control. The stages of identification and transport control process are as described below:

The RFID transponder of the vehicle is read on route and the data are transmitted to the ITS server. The RFID transponder is read when the vehicle moves along the roads, provided with readout equipment. For the successful reading of information the vehicle's speed should be no more than $80 \mathrm{kmh}$. [14]. Then the information about cargo movement is fed to server, analyzed and the aggregate information about cargo traffic is formed.

On the basis of the received information the forecast of truck traffic is formed, freight traffic is tracked, the information about the current cargo location is obtained and the time of its delivery is forecasted.

In case if there are some changes on route, the additional information should be registered in the RFID transponder through communication with the information center.

When the updated information is sent to the ITS server, the new traffic forecast is formed, new traffic flows are tracked, new information about the current cargo location is transmitted and the new time of its delivery is forecasted.

When the vehicle arrives to its destination, the information is partially deleted and the integrity of the RFID-transponder, its operating condition and the possibility of rerecording for further use are checked. C. Process of identification and transport control at stowage and shipping of the product to the final consumer

When the transport arrives to its destination, its transponder is read. If there are no discrepancies with the information, obtained from the supplier, the decision about production reception is taken. Then the vehicle is unloaded, the product quantity and quality (completeness) acceptance is performed by means of cargo units' transponders, compliance with the electronic waybill is checked, discrepancies are determined and the cargo is put in storage with entering the information about its stowed location.

When an order is received at a terminal-warehouse complex or retail facility, an electronic completeness and shipment waybill is formed. The waybill should contain the product name, its unique code, amount of product, which is to be selected, and storage location address.

Product selection is performed at storage location by means of mobile readers (the information is read from RFID-transponders). Then the cargo units are formed, the information about changes in cargo unit parameters are entered into the RFID-transponder or a new transponder is formed and attached, the outgoing control by means of RFID terminal or tunnel is performed.

Similarly to the technological process of using radio frequency identification systems in logistical systems, at the manufacture of products the information is 
recorded on a RFID-transponder, which is attached to a vehicle. Integration of radio-frequency identification technologies into the transport-and-logistics systems of the region would allow forming the advantages of three types: economical, technological and service. The described order of performing operations in the technological process of applying radio frequency identification systems in all the elements of logistical chain would allow implement it with account of the technical requirements and operational peculiarities at various process sections.

\section{CONCLUSION}

As conclusions, the following should be noted.

1. Analysis of the current trends of road freight transport functioning development allows singling out priority areas, the efficiency of implementation of which is proved by the rewarding experience in a number of developed economies.

2. The infrastructure modernization, which includes increasing the relative density of motor roads network and improving the quality of road surface and traffic network equipment, would allow improving accident record and increasing the traffic speed. 3. Intelligent transport systems, would allow performing the synchronized traffic flows control.

4. Technological innovations, which include development and implementation of the new types, models and designs of transport means, would allow improving the efficiency of transportation processes and the technologies of high-speed performance of junction operations at transportation (cargo handling operations, control procedures etc.).

5. Implementation of the presented regulations would allow creating a single supply chain, consisting of the technological cycle elements of warehouse complex of the supplier, shipper and delivery of product. Communication with a single information center (server) of the chain would permit the timely transmission and receiving of information, which in its turn makes possible the operative planning, including the cases of alterations or disruptions at certain links of the chain, by all the participants of the process.

In the scheme, presented in this article, the organization of technological process in three key links is considered manufacture of products, transportation of cargo and cargo receipt and handling at a storing or retail facility.

6. For each of the above-mentioned links of transport-logistical systems the regulations of using radio-frequency identification systems with account of technological limits of applying radiotransponders and readout equipment have been developed.

7. The volume of financing for implementing such an area as infrastructure modernization is commeasurable with budgets of a number of regions and can be realized within 8-10 years. At the same time, the problems in the transport sphere, listed above, need immediate solving with attracting investments, available for the region and the country in general. Such solutions include the implementation of intelligent systems of management, control and forecast, as well as technological solutions, which can provide the minimum time of junction operations performance. 8. Solving the problem of improving the efficiency of road freight transport functioning in logistical systems by means of automatic identification would allow considerably reducing resources consumption in the transport industry, as well as the environmental damage, by means of reducing the trucking distances and non-productive downtimes of motor transport with performing the greater amount of transport operations.

\section{REFERENCES}

[1] Marusin A.V., Ablyazov T.H. Prospects of digital transformation of logistics // Bulletin of Altai Economy and Law Academy, 2019, Vol. 4 (part 2), Pp. 240-244. - URL: https://vaael.ru/ru/article/view?id=435.

[2] Bekmurzaev I.D., Kurbanov A.H., Kurbanov T.H. Trends and stages of building logistic systems on the basis of using digital technologies // Economic and socialhumanitarian research, Vol. 20. - 2018. Pp.59.

[3] World Bank Research. - URL: https://lpi.worldbank.org/international/global/ 2018? sort=asc\&order=LPI\%20Rank\#datatabl e.

[4] Efimenko D., Demin V. Findings of the research «Development of logistics in Russia: current situation, forecast, key objectives and priorities of companies»/// Logistics, 2017, Vol. 3 (124), Pp. 14-19.

[5] Bulletin of the current trends of the Russian economy // Analytical Centre of the Government of the Russian Federation, Vol. 53, September 2019, 24 p.

[6] Gadzhinsky A. Loading and unloading operations at the warehouse. - URL: https://websklad.ru/articles/pogruzochno_ razgruzochnye_raboty_na_sklade/

[7] Gofforov Zh.Zh., Eremina I.V. Improving the efficiency of motor vehicles at transporting consumer goods // Economy. Law. Management: Contemporary issues and development trends. - 2016, Vol. 12, Pp. 2-8; Filina V.N. Issues of competitive ability of the national transport system. - URL: https:/ecfor.ru/publication/ problemykonkurentosposobnosti-natsionalnojtransportnoj-sistemy.

[8] Transport strategy of the Russian Federation for the period up to 2030. Enacted by the order of the Government of the Russian Federation on November 22, 2008. N 1734-p (in wording of the order by the Government 
of the Russian Federation as of June, 11, 2014. N 1032p). - URL: http://docs.cntd.ru/document/902132678.

[9] Vladimirov S.A. The world transport system and logistics: main courses of development // Regional economy and management: Electronic scientific journal. - URL: https://readera.org/ mirovaja-transportnajasistema-i-logistikaosnovnye-napravlenija-razvitija14322934; Vladimirov S.A. Key development trends of the world transport system and logistics // Taurian scientific reviewer. - 2016, Vol. 2 (7), Pp. 14-20. URL: https://cyberleninka.ru/ article/n/ o-klyuchevyhnapravleniyah-razvitiya-mirovoy-transportnoy-sistemyi-logistiki/viewer.

[10]Plotnikov V.A. Digitization of production: theoretical essence and development prospects in the Russian economy // Proceedings of St.Petersburg State Economic University, 2018, Vol. 4 (112). Pp. 16-24.

[11] V. V. Moiseev, V. F. Nitsevich, State policy of import substitution in modern Russia // International Journal of Pharmacy and Technology, 2016, Vol. 8 (4), Pp 2474824759; V. V. Moiseev, O. A. Sudorgin, V. F. Nitsevich, V. B. Slatinov. Government of Import Substitution as a Factor of Russian Economy Development // Smart Innovation, Systems and Technologies, 2019, Vol. 138. Pp 604-620.

[12]GOST R ISO 17363-2010. Application of radiofrequency identification (RFID) in delivery chain. Cargo containers. Effective date 2011-01-01. - URL: http://docs.cntd.ru/document/gost-r-iso-17363-2010.

[13]Directory. - URL: https://spravochnick.ru/ logistika/ transportnaya_logistika_suschnost_izadachi/ponyatie_i_ struktura_transportno-logisticheskogo_processa.

[14] Intelligent adaptive production planning and logistics systems. - URL: http://www.o-code.ru/node/343. 